\title{
Correlation of Grain Size, Stacking Fault Energy, and Texture in Cu-Al Alloys Deformed under Simulated Rolling Conditions
}

\author{
Ehab A. El-Danaf, Mahmoud S. Soliman, and Ayman A. Al-Mutlaq \\ Mechanical Engineering Department, King Saud University, P.O. Box 800, Riyadh 11421, Saudi Arabia \\ Correspondence should be addressed to Ehab A. El-Danaf; edanaf@ksu.edu.sa
}

Received 28 October 2014; Accepted 4 January 2015

Academic Editor: Ming-Xing Zhang

Copyright (C) 2015 Ehab A. El-Danaf et al. This is an open access article distributed under the Creative Commons Attribution License, which permits unrestricted use, distribution, and reproduction in any medium, provided the original work is properly cited.

\begin{abstract}
The effect of grain size and stacking fault energy (SFE) on the strain hardening rate behavior under plane strain compression (PSC) is investigated for pure $\mathrm{Cu}$ and binary $\mathrm{Cu}-\mathrm{Al}$ alloys containing 1,2, 4.7, and $7 \mathrm{wt}$. \% Al. The alloys studied have a wide range of SFE from a low SFE of $4.5 \mathrm{mJm}^{-2}$ for Cu-7Al to a medium SFE of $78 \mathrm{mJm}^{-2}$ for pure $\mathrm{Cu}$. A series of PSC tests have been conducted on these alloys for three average grain sizes of $\sim 15,70$, and $250 \mu \mathrm{m}$. Strain hardening rate curves were obtained and a criterion relating twinning stress to grain size is established. It is concluded that the stress required for twinning initiation decreases with increasing grain size. Low values of SFE have an indirect influence on twinning stress by increasing the strain hardening rate which is reflected in building up the critical dislocation density needed to initiate mechanical twinning. A study on the effect of grain size on the intensity of the brass texture component for the low SFE alloys has revealed the reduction of the orientation density of that component with increasing grain size.
\end{abstract}

\section{Introduction}

The mechanical behavior of pure metals and solid-solution alloys has been observed to be greatly influenced by microstructural parameters such as grain size, stacking fault energy (SFE), and experimental conditions [1-12]. The prevailing deformation mechanisms (slipping, twinning, and strain induced martensite) are highly dependent on the SFE of the metal. It is also dependent on the critical resolved shear stresses required for slipping and twinning which, in turn, depends on the orientation relationship of favored slip and twin systems in single and polycrystalline metals.

Twin boundaries act as barriers to dislocations in the same way as grain boundaries thus effectively reducing the slip length and enhancing the strain hardening rates. It was strongly believed that the twinning stress value was mainly controlled by the value of the SFE [4]; however there was no account for the solid-solution strengthening contribution to the flow stress. In a recent study [1], the use of $\left(\sigma-\sigma_{o}\right) / G$ was suggested for the analysis (where $\sigma$ is the flow stress during deformation, $\sigma_{o}$ is the initial yield strength, and $G$ is the shear modulus) to account for solid-solution strengthening.
The term $\left(\sigma-\sigma_{o}\right) / G$ was also believed to be an indicator of the dislocation density, as the flow stress is related to the dislocation density $\rho$ by the following equation:

$$
\sigma=\sigma_{o}+\alpha G b \rho^{1 / 2},
$$

where $b$ is the Burgers vector and $\alpha$ is a constant having a value of $\sim 1$.

In addition, it was demonstrated [1] that the value of $\left(\sigma_{t}-\sigma_{o}\right) / G$ (where $\sigma_{t}$ is the flow stress at which twinning was initiated and $\sigma_{o}$ is the initial yield strength) was nearly the same for a number of polycrystalline FCC metals deformed in simple compression with different values of SFE and having almost similar initial grain size. This suggested that there is a critical dislocation density required for twins to be initiated for the FCC alloys tested. It was concluded [1] that the primary parameters that control twin initiation are the average slip length (which can be considered to be a close parameter to the initial average grain size) and the dislocation density. The SFE was thought to have an indirect effect in promoting strain hardening (which is directly proportional to dislocation density) and in reducing the grain breakup in 
the early level of deformations which allow for twin initiation. It was found that increasing the grain size would decrease the twin nucleation stress $[2,11]$ for a given metal.

Low SFE metals such as $\mathrm{Cu}-7 \mathrm{Al}, 70 / 30$ brass, and 316L stainless steel possess high strain hardening rates due to the difficulty of cross slip $[1,6]$. Twinning generally happens when the slip system is restricted or when the critical resolved shear stress increases so that the twinning stress is lower than the stress for slip. This explains the occurrence of twins at low temperatures or high strain rates $[3,10]$. Investigation of strain hardening in medium to high SFE polycrystalline metals in uniaxial tension [11] revealed that strain hardening rate curves exhibit only stage III and stage IV known to exist in the hardening rate behavior in single crystals. In plasticity models this strain hardening behavior is incorporated by saturation type hardening laws [2]. A detailed study [1] on the strain hardening behavior of polycrystalline low SFE metals, in simple compression, revealed four distinct stages, namely, A, B, C, and D. Stage A is with a steadily decreasing strain hardening rate up to a true strain of about 0.08, similar to stage III in medium and high SFE metals. Stage B is with nearly constant strain hardening rate plateau up to a true strain of 0.2 , associated with the onset of deformation twinning. Deformation twins, being a source of hardening as discussed above, counteract the steadily decreasing hardening rate in stage $\mathrm{A}$, and this balance results in stabilizing the hardening rate giving this plateau. Stage $\mathrm{C}$ is another steadily decreasing strain hardening rate up to a true strain of 0.55 ; this was attributed to the decreasing rate of producing deformation twins. Stage D is another constant strain hardening rate plateau that prevails to high strain values, associated with twin intersections which effectively obstruct dislocation motion. It has been suggested that the SFE of the metal will have to be less than some critical value for the metal to exhibit deformation twinning [2, 8-10].

A study of tensile deformation of pure $\mathrm{Cu}$ and two $\mathrm{Cu}-\mathrm{Al}$ alloys with relatively large grain size has recently shown that pure $\mathrm{Cu}$ did not exhibit any deformation twinning at room temperature and at quasistatic testing and the propensity of deformation twinning is increased in the alloys with lower SFE and with increasing the strain rate [13]. For example, the $\mathrm{Cu}-4.5 \% \mathrm{Al}$ alloy deformed by deformation twins and the density of deformation twins increase with an increase in both strain rate and tensile strain. The distinguishing feature of this alloy was the presence of overlapping and/or intersecting twins compared to $\mathrm{Cu}-2.2 \% \mathrm{Al}$ alloy [13].

In the present study, a detailed quantitative study on the strain hardening rate in PSC of different SFE Cu-Al alloys with different grain sizes is conducted to explore new criteria for twinning under this stress state. An investigation of the effect of grain size on the intensity of the brass texture component "B" is, also, conducted. The selected state of stress here, PSC, is chosen because it simulates the rolling operation, which is an industrially important operation in metal forming.

\section{Experimental Work}

The Cu-Al alloys $(1,2,4.7$, and $7 \mathrm{wt} \% \mathrm{Al})$ were supplied as hot rolled sheets with $3 \mathrm{~mm}$ thickness. In addition, for
TABLE 1: Shear modulus $(G)$, stacking fault energy $\left(\gamma_{\mathrm{SFE}}\right)$, and normalized stacking fault energy $\gamma_{\mathrm{SFE}} /(G b)$, where $b$ is the magnitude of burgers vector, for the materials used in this study $[14,15]$.

\begin{tabular}{lccc}
\hline Material & $\begin{array}{c}G \\
(\mathrm{GPa} .)\end{array}$ & $\begin{array}{c}\mathrm{SFE}\left(\gamma_{\mathrm{SFE}}\right) \\
\left(\mathrm{mJ} / \mathrm{m}^{2}\right)\end{array}$ & $\begin{array}{c}\gamma_{\mathrm{SFE}} /(G b) \\
\left(10^{-3}\right)\end{array}$ \\
\hline OFHC Cu & 47 & 78 & 6.5 \\
$\mathrm{Cu}-1 \mathrm{Al}$ & 44.6 & 49 & 4.3 \\
$\mathrm{Cu}-2 \mathrm{Al}$ & 44.2 & 32 & 2.8 \\
$\mathrm{Cu}-4.7 \mathrm{Al}$ & 43.1 & 11 & 0.9 \\
$\mathrm{Cu}-7 \mathrm{Al}$ & 42.3 & 4.5 & 0.4 \\
\hline
\end{tabular}

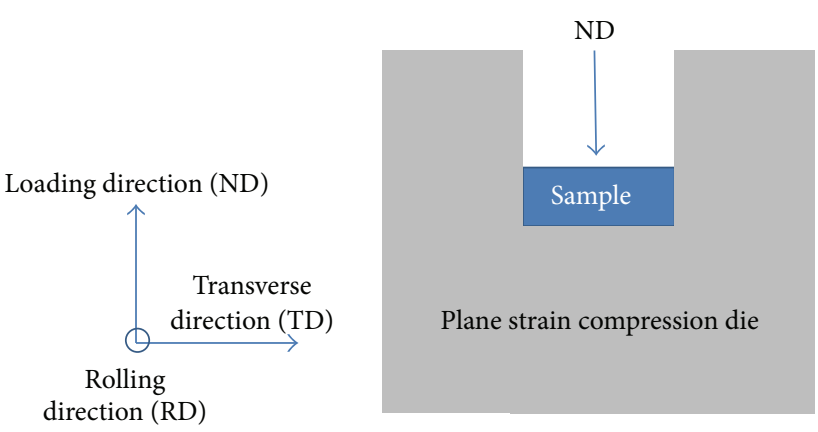

FIGURE 1: Schematic drawing of the plane strain compression die.

the purpose of comparison, oxygen-free high conductivity copper (OFHC) was tested. The OFHC was in the form of a cold rolled plate. The grain size was measured and estimated using the line intercept method. Table 1 shows the values of shear modulus and stacking fault energy for all alloys used in the current study [14-17]. Table 2 shows the different annealing treatments and thermomechanical treatment given to all alloys to achieve in each alloy three various grain sizes $(12-16 \mu \mathrm{m}, 60-80 \mu \mathrm{m}$, and $240-270 \mu \mathrm{m})$. Specimens of $12 \times 10 \times 3 \mathrm{~mm}$ were prepared. The prepared specimens were tested, under plane strain compression (PSC) using the die shown schematically in Figure 1 [15]. The tests were interrupted at strain intervals of about 0.2 axial strains for relubrication using TEFLON and high-pressure grease to nearly isolate the effect of friction from the output data. The load-displacement output data obtained from the testing machine, for each test, were corrected for machine compliance [18] and the corrected data from separate tests are reconstructed to get to the true stress and the corresponding true axial strain values.

In addition, tension tests were performed on samples with grain size of $\sim 70 \mu \mathrm{m}$, at initial strain rate of $10^{-3} \mathrm{~s}^{-1}$, using standard tensile specimens with dimensions according to ASTM standard E-8.

The deformed specimens (at selected strain levels) were prepared for metallographic examination using standard grinding and polishing procedures and then etched to reveal the microstructure. An etchant solution $(5 \mathrm{gm} \mathrm{Fe}$ $\left(\mathrm{NO}_{3}\right)_{3}, 25 \mathrm{~mL} \mathrm{HCl}$, and $70 \mathrm{~mL}$ water) was used. All optical metallographic study was carried out on sections normal to the transverse direction. 


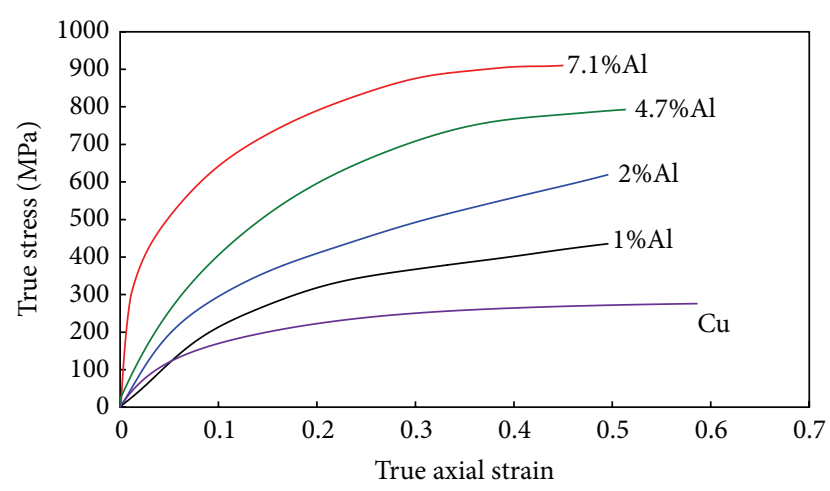

(a)

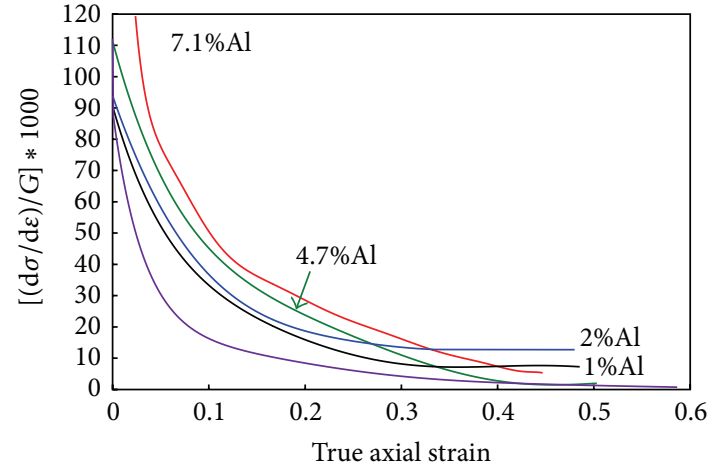

(b)

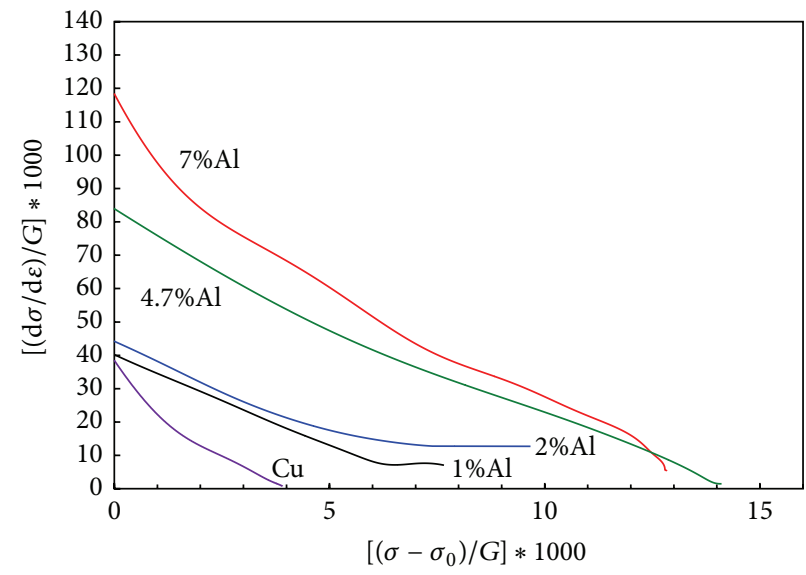

(c)

FIGURE 2: (a) True axial stress-true axial strain response for all materials with an average grain size of $15 \mu \mathrm{m}$, tested in plane strain compression. Normalized strain hardening rate versus true strain in (b) and versus normalized stress parameter in (c) for all materials displayed in part (a).

TABLE 2: Heat treatments employed to achieve three grain sizes for all materials; $\varepsilon_{0}$ is the precold deformation in plane strain compression given to the materials before annealing for the small grain sizes.

\begin{tabular}{llcc}
\hline Materials & \multicolumn{3}{c}{ Grain size } \\
& $10-15 \mu \mathrm{m}$ & $60-80 \mu \mathrm{m}$ & $240-270 \mu \mathrm{m}$ \\
\hline \multirow{2}{*}{ Copper } & Step 1: $\varepsilon_{0}=0.75$ & $750^{\circ} \mathrm{C}, 3 / 4$ & $950^{\circ} \mathrm{C}, 1$ \\
& Step 2: $460^{\circ} \mathrm{C}, 3 / 4$ hours & hours & hour \\
Cu-Al alloy & Step 1: $\varepsilon_{0}=0.4$ & As & $850^{\circ} \mathrm{C}, 1$ \\
$1 \% \mathrm{Al}$ & Step 2: $380^{\circ} \mathrm{C}, 2$ hours & received & hour \\
$\mathrm{Cu}-\mathrm{Al}$ alloy & Step 1: $\varepsilon_{0}=0.45$ & As & $850^{\circ} \mathrm{C}, 1$ \\
2\%Al & Step 2: $380^{\circ} \mathrm{C}, 2$ hours & received & hour \\
$\mathrm{Cu}-\mathrm{Al}$ alloy & Step 1: $\varepsilon_{0}=0.55$ & As & $850^{\circ} \mathrm{C}, 1$ \\
$4.7 \% \mathrm{Al}$ & Step 2: $380^{\circ} \mathrm{C}, 2$ hours & received & hour \\
$\mathrm{Cu}-\mathrm{Al}$ alloy & Step 1: $\varepsilon_{0}=0.6$ & As & $850^{\circ} \mathrm{C}, 1$ \\
$7.1 \% \mathrm{Al}$ & Step 2: $380^{\circ} \mathrm{C}, 2$ hours & received & hour \\
\hline
\end{tabular}

Crystallographic textures were obtained using a Schmiadzu X7000 diffractometer, using $\mathrm{Cu}-\mathrm{k}_{\alpha}$ radiation. For Xray diffraction, samples were mechanically ground to 1000 grit size paper and mechanically polished. Texture was investigated along the mid-thickness of RD-TD plane. The (100), (110), and (111) pole figures were measured. The raw data were corrected for background and defocusing using a correction file generated from an aluminum sample with a random texture. Recalculated pole figures and orientation distribution function (ODF) plots are generated by the iterative series expansion method with a maximum order of 22, which gives the volume fraction of grains oriented along a certain ideal orientation defined with Euler angles representation $\left(\phi_{1} \phi \phi_{2}\right)$ in Bunge's notation.

\section{Results}

3.1. PSC Testing. The normalized strain hardening rate values, corrected for machine compliance, were calculated and correlated with the normalized stress parameter $\left(\sigma-\sigma_{o}\right) / G$ (where $\sigma$ is the flow stress during deformation, $\sigma_{o}$ is the initial yield strength, and $G$ is the shear modulus) and versus the true strain $(\varepsilon)$. The normalized stress parameter $\left(\sigma-\sigma_{o}\right) / G$ was chosen to reflect the dislocation density built inside the materials during plastic deformation. Figure 2(a) shows the true stress-true strain response for all alloys tested for nearly similar grain size of about $15 \mu \mathrm{m}$. Strain hardening rate $(\mathrm{d} \sigma / \mathrm{d} \varepsilon)$ computed from the stress-strain data normalized by shear modulus is plotted against accumulated plastic true strain in Figure 2(b) and against $\left(\sigma-\sigma_{o}\right) / G$ in Figure 2(c). 


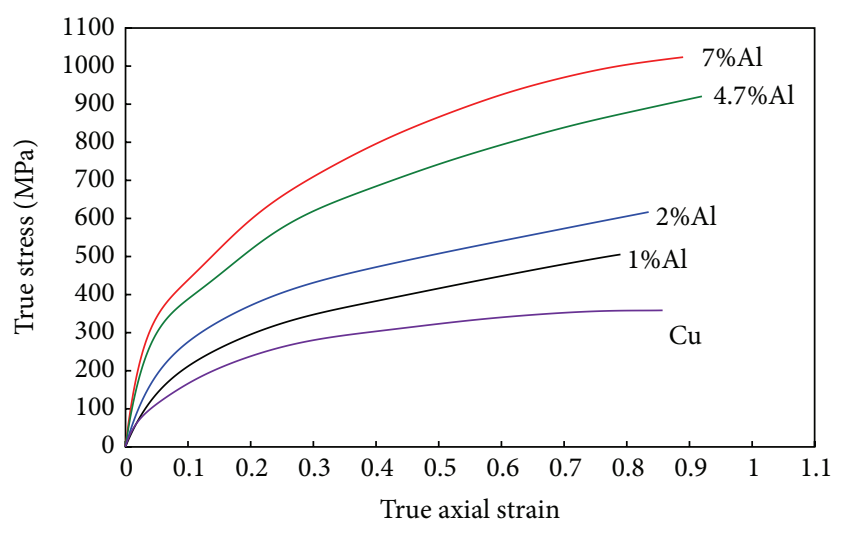

(a)

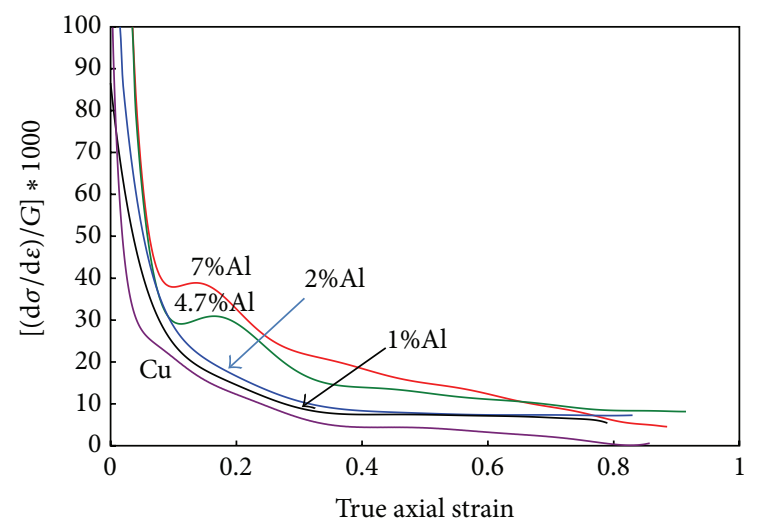

(b)

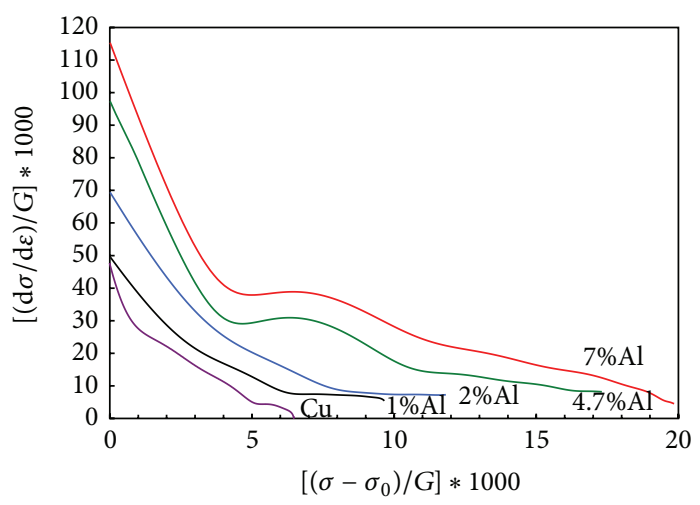

(c)

Figure 3: (a) True stress-true strain response for all materials with an average grain size of $70 \mu \mathrm{m}$, tested in plane strain compression. Normalized strain hardening rate versus true strain in (b) and versus normalized stress parameter in (c) for all materials displayed in part (a).

At early stages, up to a strain of about 0.1 , the hardening rate drops sharply, similar to stage A discussed above for simple compression (SC) for low SFE materials and stage III in the case of medium and high SFE materials, both attributed to dynamic recovery and cross slipping. From that strain onwards, the hardening rate remains decreasing but at a lower rate, similar to stage IV observed in medium and high SFE materials. It is obvious that as the SFE decreases the hardening rate values, for the same normalized stress level, increase. It is observed that the hardening rate response is composed of two stages, similar to the hardening rate behavior of medium and high SFE materials discussed in simple compression [2].

Figure 3(a) shows the true stress-true strain response for all materials at an average grain size of about $70 \mu \mathrm{m}$. The normalized hardening rate is plotted against true plastic strain in Figure 3(b) and against the normalized stress parameter in Figure 3(c). Hardening rate for $\mathrm{Cu}-7 \mathrm{Al}, \mathrm{Cu}-$ $4.7 \mathrm{Al}$ displays four distinct stages. Stage $\mathrm{A}$ is the stage in which the hardening rate drops sharply up to a strain of about 0.1 ; then stage B takes over in which there is a constant plateau of hardening rate; this stage and the breaking of the continuously decreasing hardening rate values in stage A are attributed to the onset of primary twinning which gives a source of hardening. Then stage $\mathrm{C}$ starts with continuously decreasing hardening rate up to a strain of about 0.4 .
After this strain level, stage D starts where the hardening rate continues dropping but at a lower rate compared to stage C. It is worth mentioning that stage D observed in PSC is much smaller as compared to the one observed in SC [1]. Stage D is mainly attributed to twin intersection which is another source of hardening since it constitutes an effective barrier to dislocation motion; in the case of PSC and at these strain levels shear bands which are a source of softening become appreciable. This explains why stage $\mathrm{D}$ is diminished, more clearly as shown in Figure 3(c). The $\left(\sigma-\sigma_{o}\right) / G$ value corresponding to the transition from the steadily decreasing hardening stage $\mathrm{A}$ to the constant hardening rate plateau $\mathrm{B}$ can be considered as the normalized twinning stress $\left(\sigma_{t}-\right.$ $\left.\sigma_{o}\right) / G$, since this transition point corresponds to the onset of deformation twinning in the microstructure. It is noted that $\left(\sigma_{t}-\sigma_{o}\right) / G$ at the onset of stage $\mathrm{B}$ for $\mathrm{Cu}-7 \mathrm{Al}$ and $\mathrm{Cu}-4.7 \mathrm{Al}$ is 0.0043 and 0.0041 , respectively. Hardening rate for $\mathrm{Cu}-2 \mathrm{Al}$, $\mathrm{Cu}-1 \mathrm{Al}$, and copper displays two stages similar to that of high SFE materials discussed above.

Figure 4(a) shows the true stress-true strain response for all alloys at an average grain size of about $250 \mu \mathrm{m}$ and the normalized hardening rate plotted against true strain in Figure 4(b) and against the normalized stress parameter in Figure 4(c). Strain hardening rate of $\mathrm{Cu}-1 \mathrm{Al}$ and copper still displays only two stages. $\mathrm{Cu}-2 \mathrm{Al}$ displays almost the two stages as the $\mathrm{Cu}-1 \mathrm{Al}$ and copper but with a short diminished 


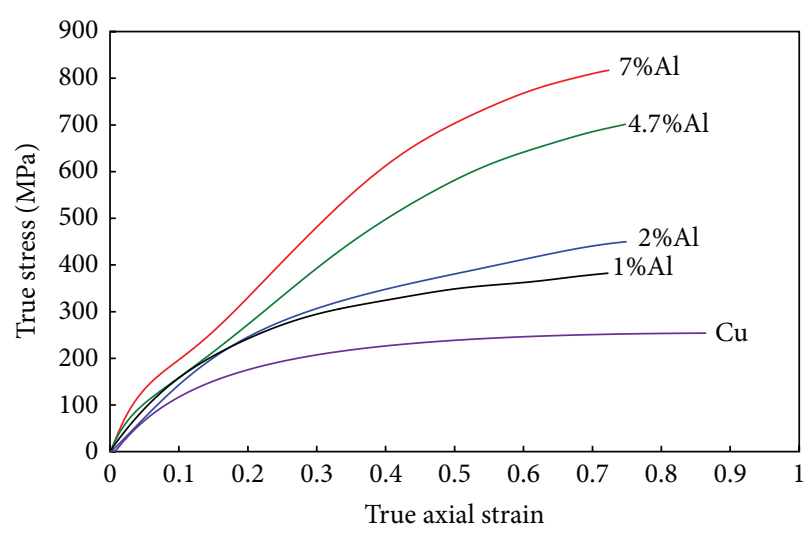

(a)

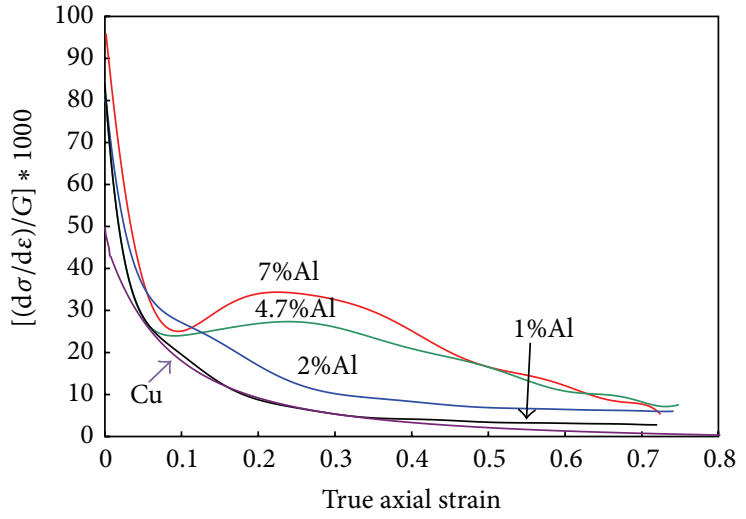

(b)

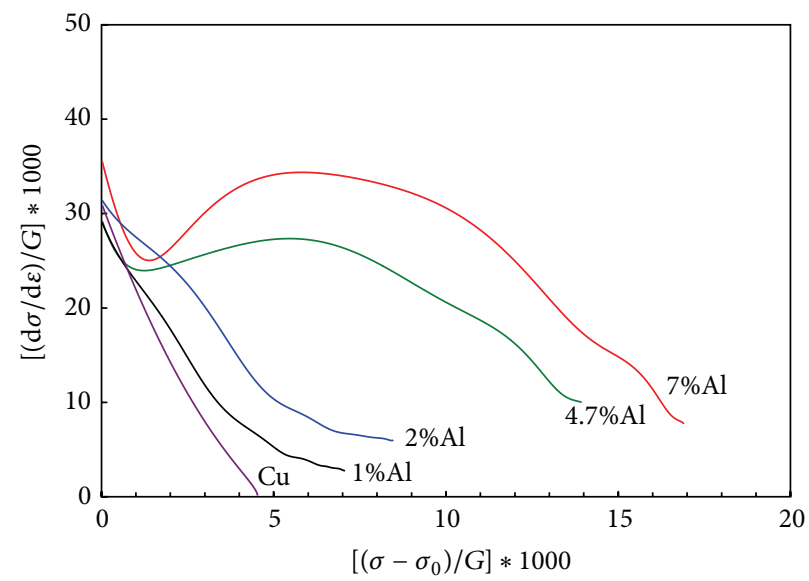

(c)

FIgURE 4: (a) True stress-true strain response for all materials with an average grain size of $250 \mu \mathrm{m}$, tested in plane strain compression. Normalized strain hardening rate versus true strain in (b) and versus normalized stress parameter in (c) for all materials displayed in part (a).

stage $B$ that is not even maintained at a constant hardening rate value. This stage is marked for a continuously dropping strain hardening that is distinctly happening at a lower rate compared to stage A. This could be an indication to some twinning that is not sufficient to fully counteract the softening associated with dynamic recovery in stage A. Hardening rate for $\mathrm{Cu}-7 \mathrm{Al}, \mathrm{Cu}-4.7 \mathrm{Al}$ displays the four distinct stages; it is obvious that stage B is greatly enhanced in these alloys and this could be attributed to the higher amount of deformation twins. It is noted that $\left(\sigma_{t}-\sigma_{o}\right) / G$ at the onset of stage B for $\mathrm{Cu}-7 \mathrm{Al}$ and $\mathrm{Cu}-4.7 \mathrm{Al}$ is 0.0013 and 0.0011 , respectively.

The above figures (Figures 2-4) show the effect of SFE excluding the effect of grain size. To be able to show the effect of grain size and to avoid repetition, the stress-strain responses and the hardening rate for $\mathrm{Cu}-7 \mathrm{Al}$ for the three grain sizes are displayed in Figure 5. The presence of stage $\mathrm{B}$ behavior for the grain sizes of 70 and $250 \mu \mathrm{m}$ is clear. The higher hardening rate for the smaller grain size $(15 \mu \mathrm{m})$ at early strain levels (up to a strain 0.1) is, also, obvious.

3.2. Tensile Testing. Figure 6 shows the true stress-true strain response in tensile testing for all alloys for the grain size of $\sim 70 \mu \mathrm{m}$. The engineering stress strain curves demonstrated that the strength and elongation percent increase with $\mathrm{Al}$ content. Figures 6(b) and 6(c) represent the normalized hardening rate plotted against true strain and against the normalized stress parameter, respectively. It is noted that $\left(\sigma_{t}-\sigma_{o}\right) / G$ at the onset of stage $\mathrm{B}$ for $\mathrm{Cu}-7 \mathrm{Al}$ and $\mathrm{Cu}-4.7 \mathrm{Al}$ is 0.0038 and 0.0037 , respectively.

3.3. Microstructure. Figure 7 represents the deformed microstructure of medium grain size at true axial strain of 0.5 for $\mathrm{Cu}-4.7 \mathrm{Al}$ and $\mathrm{Cu}-7 \mathrm{Al}$ alloys. Microstructure for these two alloys reveals the propensity of mechanical twinning and also features of twin intersections. Figures 8(a) and 8(b) show the microstructure for $\mathrm{Cu}-2 \mathrm{Al}$ at axial strain of 0.5 for grain size of 70 and $250 \mu \mathrm{m}$, respectively. At $70 \mu \mathrm{m}$ no sign of deformation twinning was observed in the microstructure, whereas in the $250 \mu \mathrm{m}$ some twinning was observed though its existence was scarce.

\section{Discussion}

4.1. Strain Hardening Rate Analysis and Deformation Twinning Criterion. The $\left(\sigma-\sigma_{o}\right) / G$ is depicted to reflect the dislocation density built inside the material during plastic 


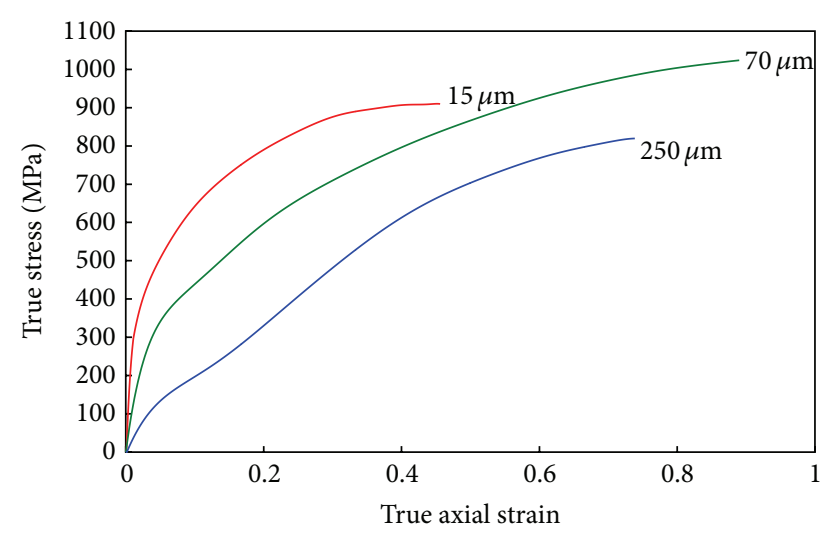

(a)

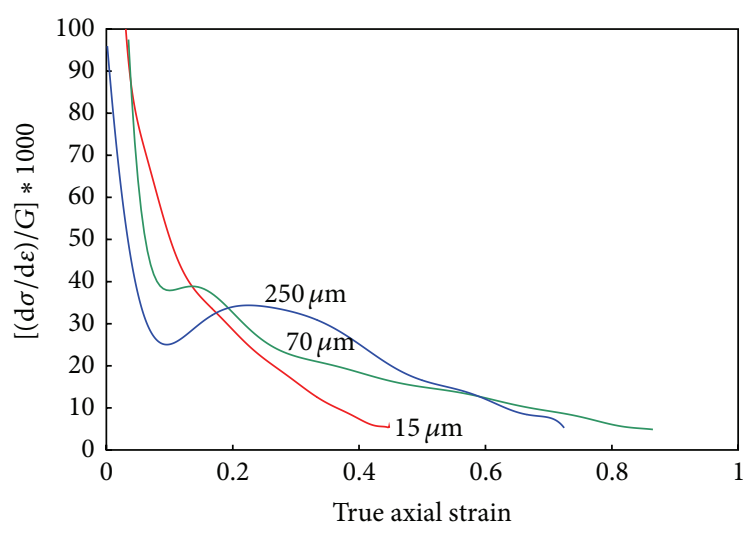

(b)

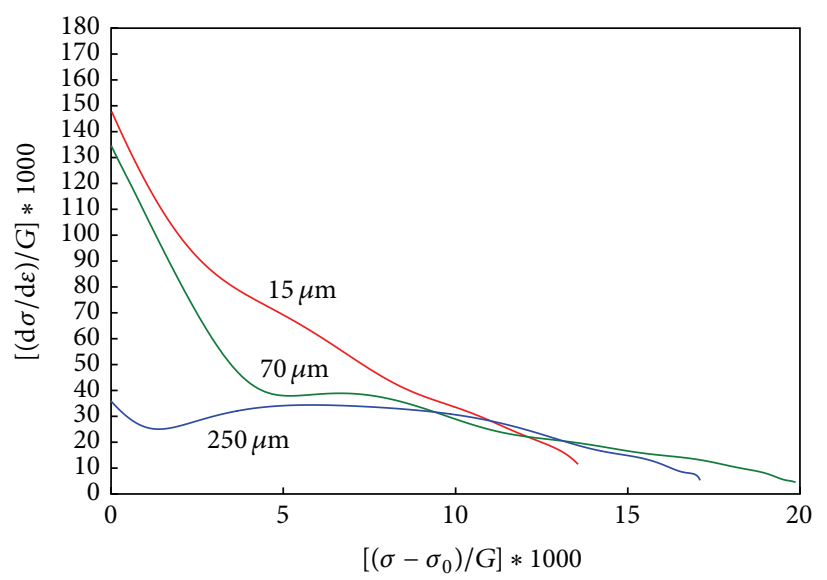

(c)

Figure 5: (a) True stress-true strain response for $\mathrm{Cu}-7 \mathrm{Al}$ for all three grain sizes, tested in plane strain compression. Normalized strain hardening rate versus true strain in (b) and versus normalized stress parameter in (c) for all materials displayed in part (a).

deformation. Taking this value at the onset of stage B (formation of primary twinning) would correspond to the critical dislocation density required for twin initiation. Plotting the $\left(\sigma_{t}-\sigma_{o}\right) / G$ (where $\sigma_{t}$ is the flow stress at twin initiation) at the onset of stage B for the 70 and $250 \mu \mathrm{m}$ against the normalized SFE $(\gamma / G b)$ for the $\mathrm{Cu}-7 \mathrm{Al}, \mathrm{Cu}-4.7 \mathrm{Al}$ alloys yields the results shown in Figure 9. These are the two materials that displayed the four stages of hardening for the two grain sizes. It is observed that the value of $\left(\sigma_{t}-\sigma_{o}\right) / G$ is more or less constant for each set of grain size being about 0.0042 for $70 \mu \mathrm{m}$ and 0.0012 for $250 \mu \mathrm{m}$. Also added, for the same two alloys and for a grain size of $15 \mu \mathrm{m}$ which did not display twinning, is the value of $\left(\sigma_{t}-\sigma_{o}\right) / G$ that was calculated at a strain of about 0.1 . This was performed because this was performed as this was the strain for which twinning was initiated for the other two grain sizes. The constant value of $\left(\sigma_{t}-\sigma_{o}\right) / G$ for each set of grain size when plotted against the normalized SFE shows that there is no direct dependence on the SFE since the normalized stress parameter did not change for the different SFE materials of the same grain size. This shows that grain size is a major controlling parameter in the process of twin initiation. The results also show that there is a critical dislocation density that needs to be available for each grain size in order for twins to nucleate. It is obvious that the larger grain size requires less normalized twinning stress or in other words less critical dislocation density. According to (1) the dislocation density, corresponding to $\left(\sigma_{t}-\sigma_{o}\right) / G$ of 0.0042 for $70 \mu \mathrm{m}$ and 0.0012 for $250 \mu \mathrm{m}$ for $\mathrm{Cu}-7 \mathrm{Al}$, is calculated to be $2.8 \times 10^{14} \mathrm{~m}^{-2}$ for $70 \mu \mathrm{m}$ and $1.5 \times 10^{13} \mathrm{~m}^{-2}$ for $250 \mu \mathrm{m}$.

Calculating the corresponding value of equivalent von Mises stress for the normalized stress parameter associated with twinning in PSC for $\mathrm{Cu}-7 \mathrm{Al}$ and $\mathrm{Cu}-4.7 \mathrm{Al}$ alloys of the same grain size of $70 \mu \mathrm{m}$ gives $0.0043 / 1.154=0.0037$ for $\mathrm{Cu}-7 \mathrm{Al}$ and $0.0041 / 1.154=0.0035$ for $\mathrm{Cu}-4.7 \mathrm{Al}$. Comparing these Von Mises values with those obtained in tensile testing yields reasonable agreement $\left(\left(\sigma_{t}-\sigma_{o}\right) / G\right.$ at the onset of stage $\mathrm{B}$ for $\mathrm{Cu}-7 \mathrm{Al}$ and $\mathrm{Cu}-4.7 \mathrm{Al}$ is 0.0038 and 0.0037 , resp., in tensile testing). This suggests that the stress required for the onset of primary twinning is independent of stress state but rather on a critical dislocation density built inside the material due to the deformation process.

To establish a criterion for deformation twinning and since only two grains sizes (250 and $70 \mathrm{~mm}$ ) in $\mathrm{Cu}-4.7 \mathrm{Al}$ and $\mathrm{Cu}-7 \mathrm{Al}$ exhibited twinning, it was necessary to characterize the response of these two alloys for an intermediate grain 


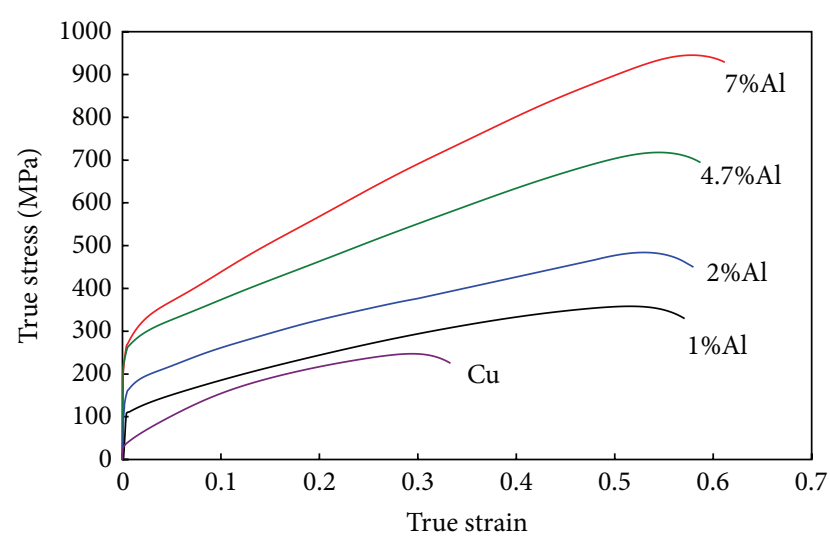

(a)

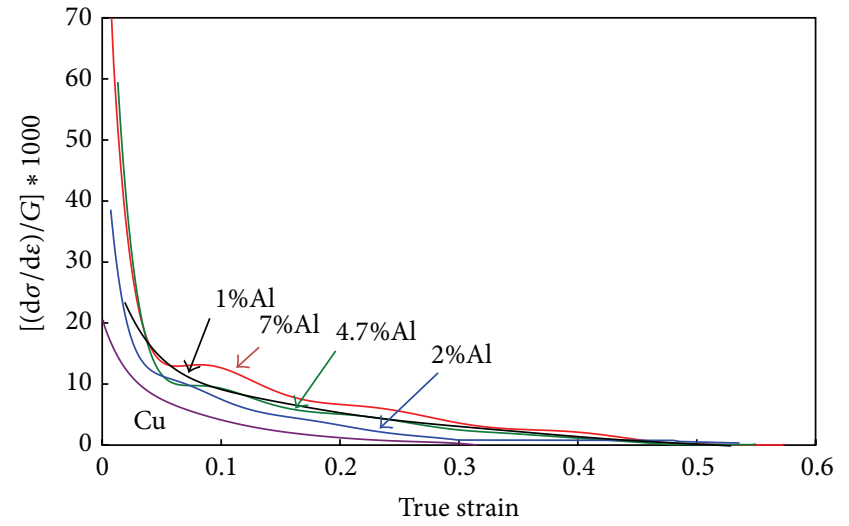

(b)

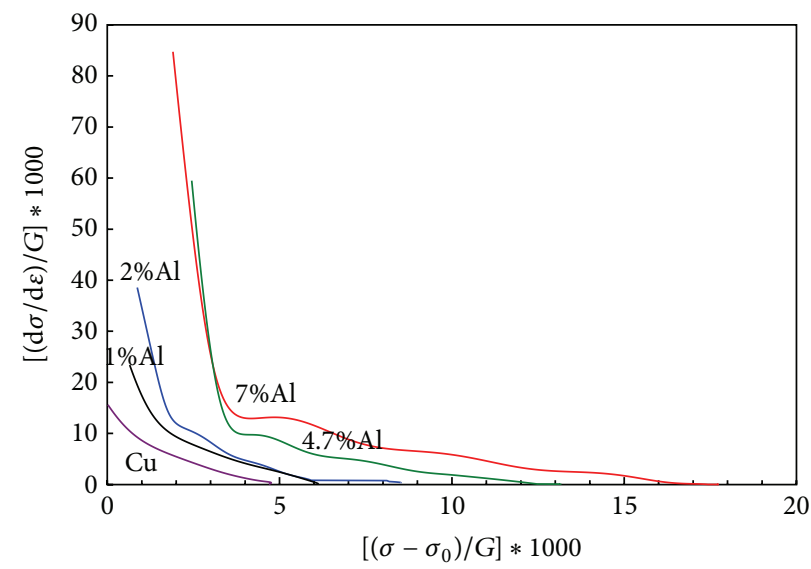

(c)

FIGURE 6: True stress-true strain response for all materials with an average grain size of $70 \mu \mathrm{m}$, tested in tension. Normalized strain hardening rate versus true strain in (b) and versus normalized stress parameter in (c) for all materials displayed in part (a).

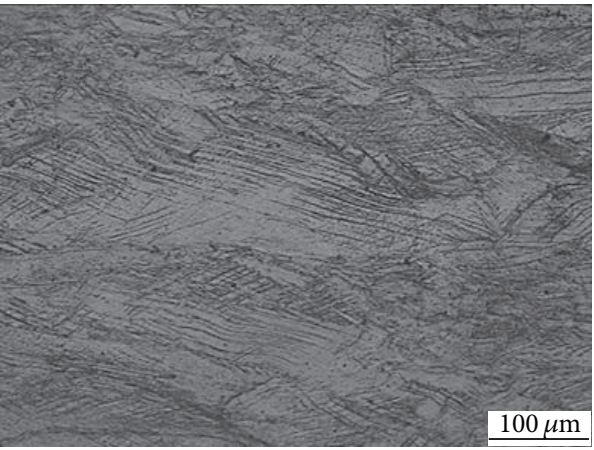

(a)

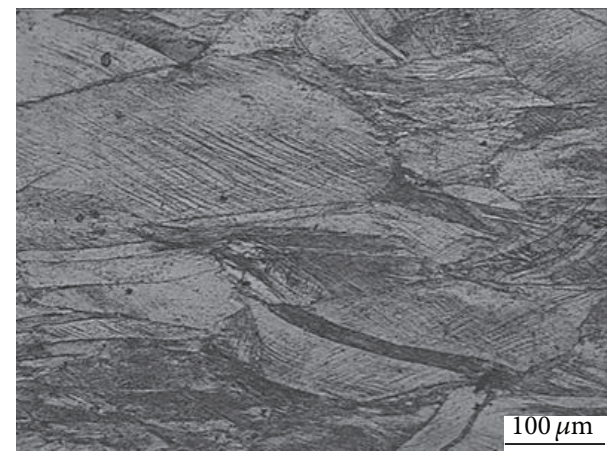

(b)

Figure 7: (a, b) Microstructure of the $70 \mu \mathrm{m} \mathrm{Cu}-4.7 \mathrm{Al}$ and $\mathrm{Cu}-7 \mathrm{Al}$ deformed to true axial strains of 0.5 in plane strain compression on the transverse section, respectively.

size. Thus, both alloys were annealed at $600^{\circ} \mathrm{C}$ for $1 \mathrm{hr}$ to yield a grain size of about $120 \mu \mathrm{m}$ and subsequently tested in plane strain compression under the same experimental conditions. Both alloys, for a grain size of $120 \mu \mathrm{m}$, exhibited a hardening rate response similar to that observed for the other two grain sizes in terms of having the four hardening stages. Figure 10 presents a log-log plot of the values of $\left(\sigma_{t}-\sigma_{o}\right) / G$ at the onset of stage B against initial grain size for the two alloys that exhibited deformation twins, $\mathrm{Cu}-4.7 \mathrm{Al}$ and $\mathrm{Cu}-7 \mathrm{Al}$ for the three grain sizes of 70,120 , and $250 \mu \mathrm{m}$. It is observed that all points fall on a segment of a straight line which presents a criterion for twinning in PSC for $\mathrm{Cu}-\mathrm{Al}$ alloys under the present experimental conditions. 


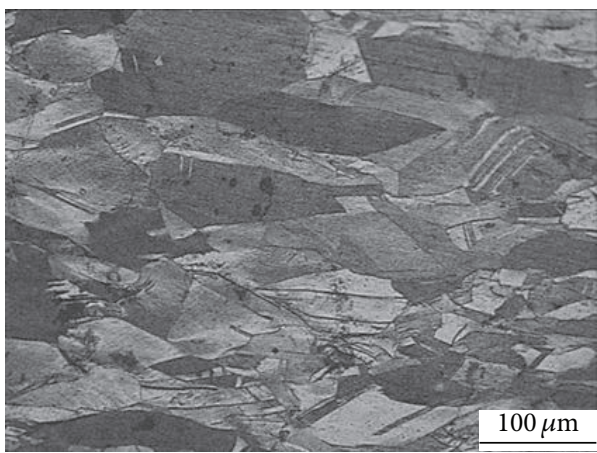

(a)

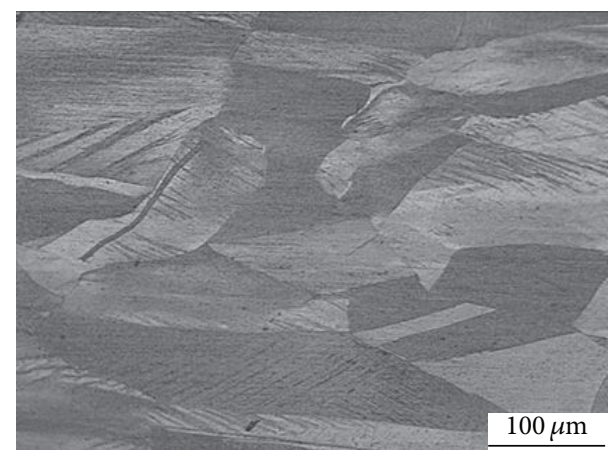

(b)

Figure 8: $(\mathrm{a}, \mathrm{b})$ Microstructure of $\mathrm{Cu}-2 \mathrm{Al}$ deformed to true axial strains of 0.5 in plane strain compression on the transverse section, for $70 \mu \mathrm{m}$ and $250 \mu \mathrm{m}$, respectively.

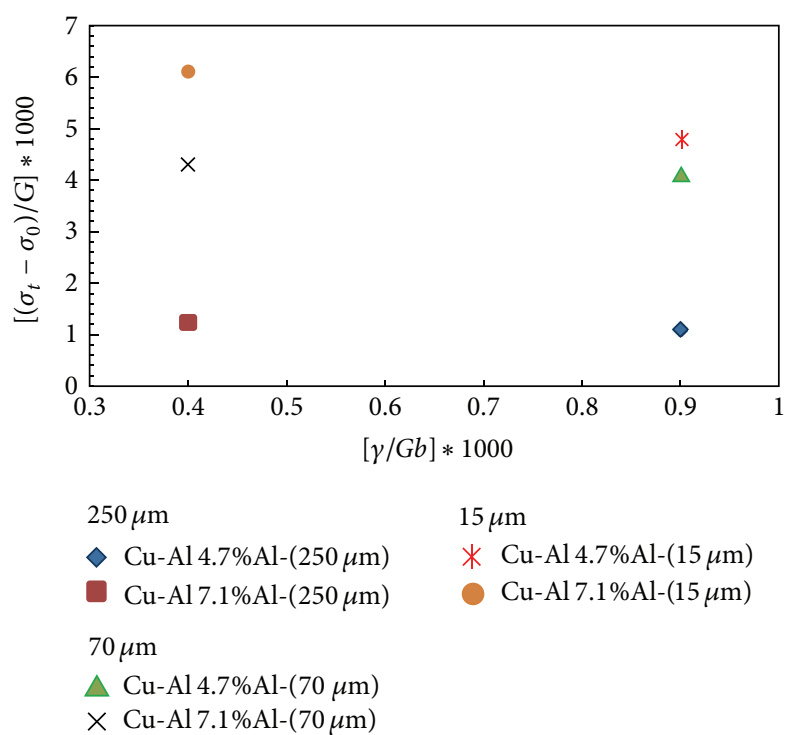

Figure 9: $\left[\left(\sigma_{t}-\sigma_{o}\right) / G\right] * 1000$ at the onset of stage B for materials that displayed stage $\mathrm{B}(\mathrm{Cu}-4.7 \mathrm{Al}$ and $\mathrm{Cu}-7 \mathrm{Al})$ for the 70 and $250 \mu \mathrm{m}$ and at strain of 0.1 for the $15 \mu \mathrm{m}$ which did not display stage $\mathrm{B}$ versus normalized stacking fault energy $[\gamma / G b] * 1000$.

The criteria confirm the above finding; that is, increasing the initial grain size reduces the normalized twinning stress. The best fit can be expressed as a power law as

$$
\frac{\left(\sigma_{t}-\sigma_{o}\right)}{G}=0.28 d^{-0.99}
$$

where $d$ is the average initial grain size in $\mu \mathrm{m}$.

Equation (2) is in harmony with the approach $[19,20]$ that proposes that the shear stress required to activate a twinning dislocation source is given by the shear stress to activate a Frank-Read source, $\tau_{\mathrm{F}-\mathrm{R}}$ :

$$
\tau_{\mathrm{F}-\mathrm{R}}=\frac{G b}{2 R},
$$

where $R$ is the radius of the dislocation source. As twins are mainly nucleated at grain boundaries and the radius of

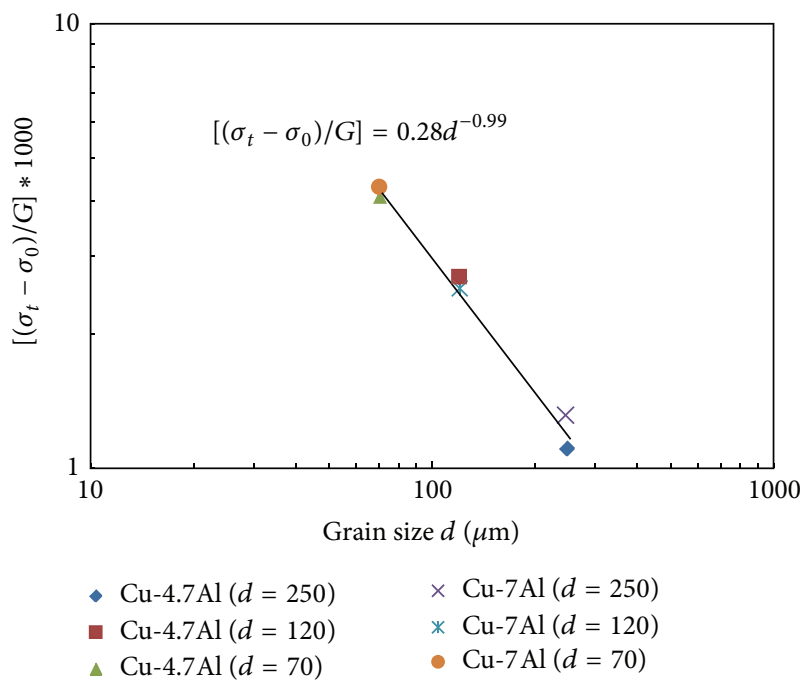

Figure 10: Normalized stress parameter $\left[\left(\sigma_{t}-\sigma_{o}\right) / G\right] * 1000$ versus initial grain size for materials that displayed stage $\mathrm{B}$ and consequently twinning $(\mathrm{Cu}-4.7 \mathrm{Al}$ and $\mathrm{Cu}-7 \mathrm{Al})$.

the softest possible dislocation source is proportional to the grain size, the following relation for the critical resolved shear stress for twinning is proposed $[19,20]$ :

$$
\tau_{\mathrm{tw}}=\frac{G b}{d},
$$

where $d$ is the grain size. This equation only describes the stress for nucleation of twins on boundaries and is in qualitative agreement with the prediction of (2).

It is concluded that materials will exhibit deformation twinning, provided that they develop a normalized stress value at a strain of about 0.1 , compared to the values presented by the fitted line. This can be interpreted that $\left(\sigma-\sigma_{o}\right) / G$ or the dislocation density has reached a critical value required for twin formation at the appropriate strain level. Thus the strain hardening rate has to be high enough to build the flow stress level which is a subsequent proportional parameter to the dislocation density at an early enough strain level. This high 
hardening rate is available in low SFE materials where cross slipping of dislocation is difficult. Thus there is a better chance for low SFE materials to meet this twinning criterion. Similar form to (2) was reported for a group of low SFE alloys in simple compression [2] where the dependence of normalized twinning stress on the initial grain size also took an inverse proportional trend. The power on the grain size parameter was -0.89 compared to -0.99 reported in the current study for plane strain compression. It is worth comparing these values to the power of the grain size for the Hall-Petch relation, which is known to be -0.5 . The original dislocation model for the Hall-Petch equation was based on the concept that grain boundaries act as barriers to dislocation motion, but there was no twinning involved in the model. To be able to explain the difference in the power values around $\sim-1.0$ in the current case for twinning versus -0.5 in the HallPetch, further investigation is needed. Recent investigation on twinning in a magnesium alloy [21] showed that twins first appear in large grains and that only with increasing strain smaller grains tend to twin. This may explain the decrease in twinning stress with increasing grain size.

4.2. Texture Evolution. Shear banding is a major deformation mechanism that can lead to softening and subsequently to failure in an important industrial processing technique such as rolling. Shear bands consist of very small-elongated crystallites that are separated by high angle boundaries. The propensity of shear banding in PSC is well established [22, 23].

It was reported earlier [15] that for the $70 \mu \mathrm{m}$ grainsize materials, used in the current investigation under plane strain compression, there is a marked propensity of shear banding for the 4.7 and $7 \mathrm{wt} \% \mathrm{Al}$ and the shear bands extend over few grains (macroscale shear banding), whereas for the other two alloys ( 1 and $2 \mathrm{wt} \% \mathrm{Al}$ ) the bands were confined within the grains. A previous study [23] on a group of FCC metallic alloys (316 stainless steel, 70/30 Cu-Zn, 80/20 Cu$\mathrm{Zn}, 90 / 10 \mathrm{Zn}, \mathrm{Cu}$ ) showed that shear banding happens much faster and becomes more extensive at early strain levels in small grain sized low and medium SFE materials. This study was conducted through extensive investigation of the evolved microstructure under plane strain compression as well as through detailed investigation of the strain hardening rates. One outcome of this study [23] for 70/30 brass is that strain at which shear banding becomes visible in the microstructure on the transverse section is $0.58,0.36$, and 0.15 for the grain sizes of 250,50 , and $10 \mu \mathrm{m}$, respectively. This shows that shear banding becomes more progressive and dominant as the grain size is reduced. The suppression of deformation twinning, which partially accommodates the imposed plastic deformation, in small grain sized low SFE materials can be a strong reason for the pronounced shear banding in these materials, under the condition of small grain size. Shear banding, thus, becomes a dominant deformation mechanism in small grain sized material in plane strain compression.

The texture development of cold rolled FCC metals can best be described by orientation concentrations along two fibers, the $\alpha$ fiber ( $\langle 110\rangle$ parallel to the sheet normal) and the $\beta$ fiber ( $\langle 110\rangle$ tilted $60^{\circ}$ towards the rolling direction). The density along these lines has been repeatedly discussed in the literature [24-26]. The $\alpha$ fiber extends from the Goss $(G)$ orientation $\left\{\begin{array}{lll}0 & 1 & 1\end{array}\right\}\left\langle\begin{array}{llll}1 & 0 & 0\end{array}\right.$ to the $\left\{\begin{array}{lll}0 & 1 & 1\end{array}\right\}\left\langle\begin{array}{lll}2 & 1 & \overline{1}\end{array}\right\rangle \mathrm{B}$ orientation (brass component). The $\beta$ fiber extends through three main

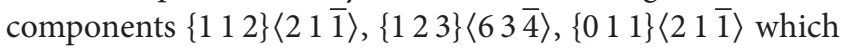
are referred to as $\mathrm{Cu}$ (copper), $\mathrm{S}$, and $\mathrm{B}$ (brass) orientations, respectively. It has been always reported that rolling of medium and high stacking fault energy metals yields copper type texture, but for low stacking fault energy metals the texture is characterized with brass type texture (a strong B component) [27]. Sevillano et al. [28] reported that the incidence of shear bands is greater in low SFE than in high SFE materials and affirmed that shear bands are present in rolled FCC metals of low SFE from the point at which the brass-type texture starts to form. The copper to brass transition of the rolling texture that happens at intermediate rolling reductions with lowering the SFE has been thoroughly discussed by [25-30] and recently analyzed by El-Danaf et al. [15].

Figures 11(a)-11(b) present the orientation distribution function plots (ODF) for the $15 \mu \mathrm{m}$ and $250 \mu \mathrm{m}$ of $\mathrm{Cu}-4.7 \mathrm{Al}$, respectively. Figures 11 (c)-11(d) present the ODF plots for the $15 \mu \mathrm{m}$ and $250 \mu \mathrm{m}$ of $\mathrm{Cu}-7 \mathrm{Al}$, respectively. The samples presented in Figure 11 are those plane strain samples compressed to a true axial strain of about 1.0 , which corresponds to a rolling reduction of about $63 \%$. The orientation density $f(g)$ of the B orientation was calculated and presented as a function of the initial grain size in Figure 12, for both alloys. The $\operatorname{ODF}(g)(f(g))$ reflects the volume fraction of grains oriented along a certain direction $g$ and for an angular bounding range $(\mathrm{dg})$ of $5^{\circ}$. Both alloys displayed the same trend of reduction in the intensity of the $\mathrm{B}$ orientation with increasing the initial grain size in plane strain compression. This shows that small grained materials, which exhibit excessive shear band localization and almost no twinning, display a pronounced intensity of the $\mathrm{B}$ orientation and increasing the grain size of the same alloy, which is a condition of producing more deformation twins, is accompanied by a reduction in the orientation density of the $\mathrm{B}$ orientation.

Two land mark investigations on the texture evolution in rolling of 70/30 brass (low SFE FCC alloy) for two different grain sizes revealed interesting details about the effect of grain size on the evolution of rolling texture. One study [30] was conducted on fine grained $70 / 30$ brass $(2-5 \mu \mathrm{m})$; the other study was conducted on a $35 \mu \mathrm{m}$ grain sized $70 / 30$ brass [25]. The processing was conducted via rolling in both studies to different rolling reductions. The orientation densities $f(g)$ of the $\mathrm{B}$ orientation is depicted from both studies and reported here in Table 3 for the respective rolling reductions. It is obvious that both grain sizes developed a brass type texture but it is also evident the strong and sharp build-up of the B component for the small grain sized material. This falls into the hypothesis that shear bands promote the transition from copper type to brass type texture. It was experimentally observed [29] in a previous study, conducted in plane strain compression of $\mathrm{Cu}-\mathrm{Zn}$ alloys, that transition from copper to brass type texture was mainly controlled and correlated with shear banding rather than twinning. 


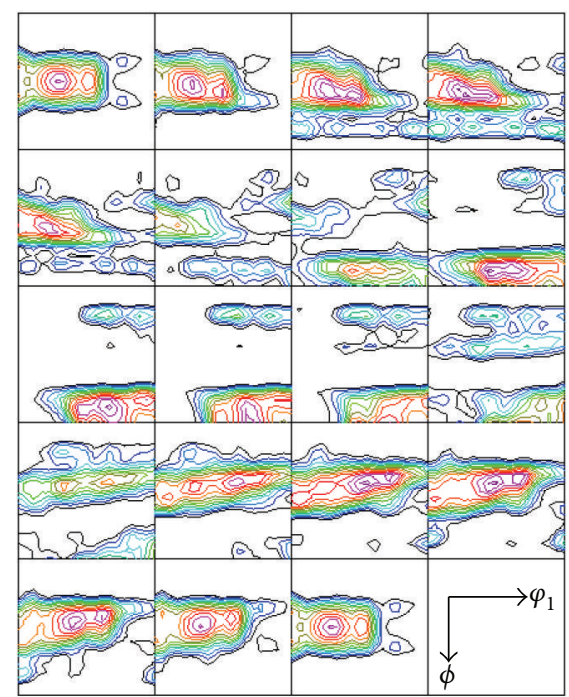

Contour levels:

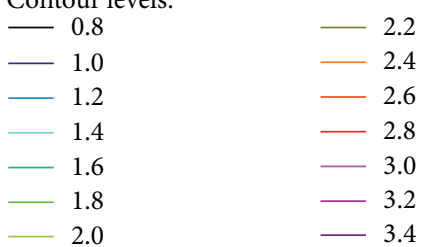

(a)

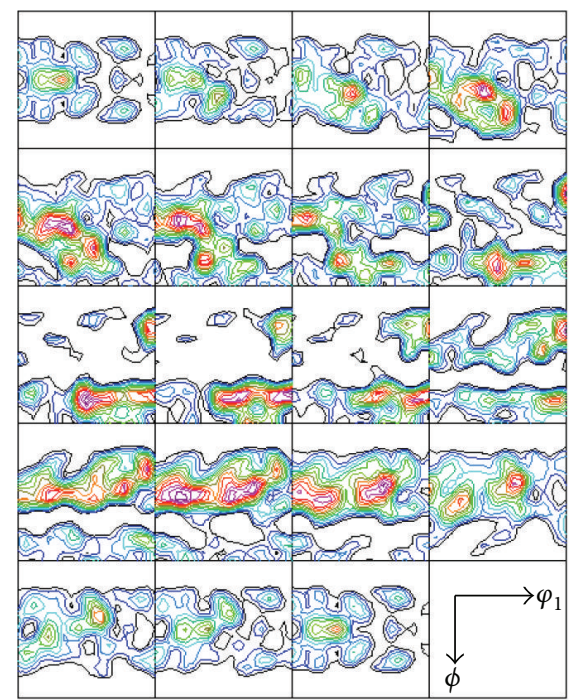

Contour levels:

$\begin{array}{rr}-0.5 & -\quad 4.0 \\ -1.0 & -5.5 \\ -1.5 & -5.0 \\ 2.0 & -5.5 \\ 2.5 & -6.0 \\ -3.0 & -6.5 \\ -3.5 & -7.0\end{array}$

(c)

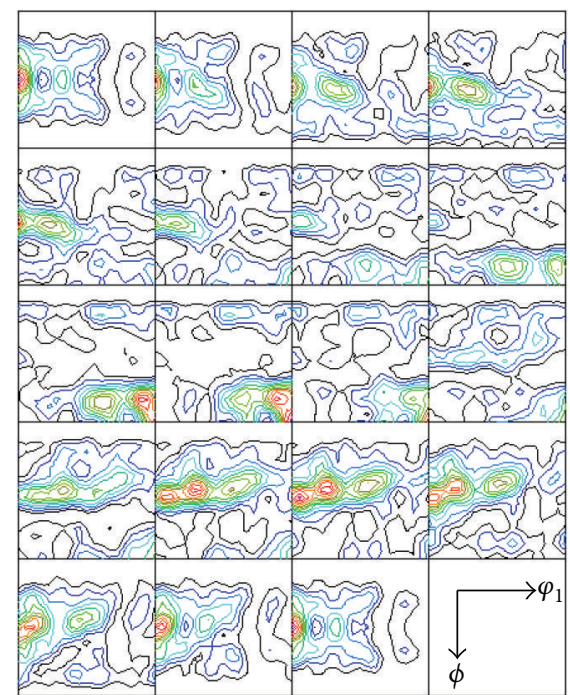

Contour levels:

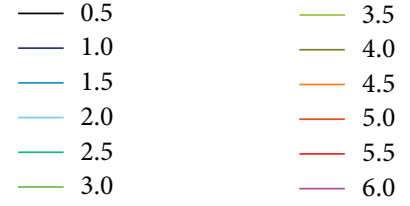

(b)

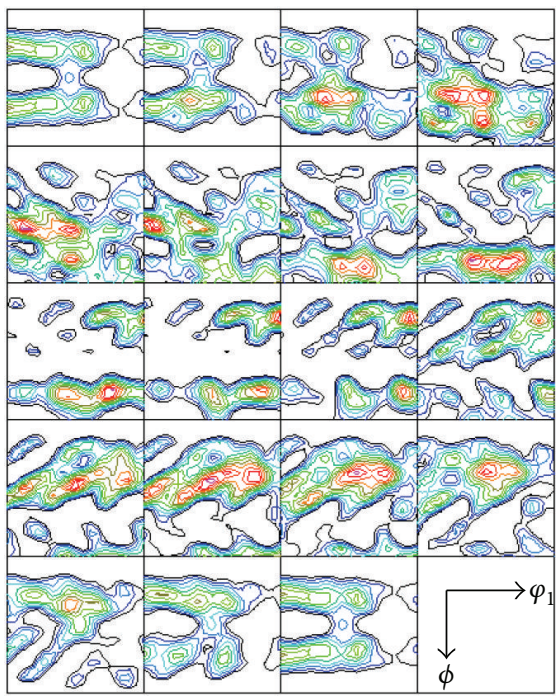

Contour levels:

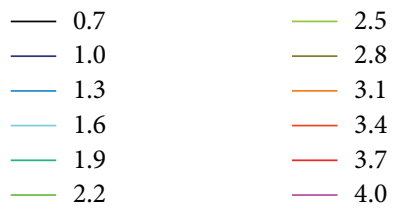

(d)

Figure 11: ODF plots for $\mathrm{Cu}-4.7 \mathrm{Al}$ for $15 \mu \mathrm{m}$ in (a) and $250 \mu \mathrm{m}$ in (b) and for $\mathrm{Cu}-7 \mathrm{Al} 15 \mu \mathrm{m}$ in (c) and $250 \mu \mathrm{m}$ in (d). All samples were plane strain compressed to a true axial strain of 1.0. 


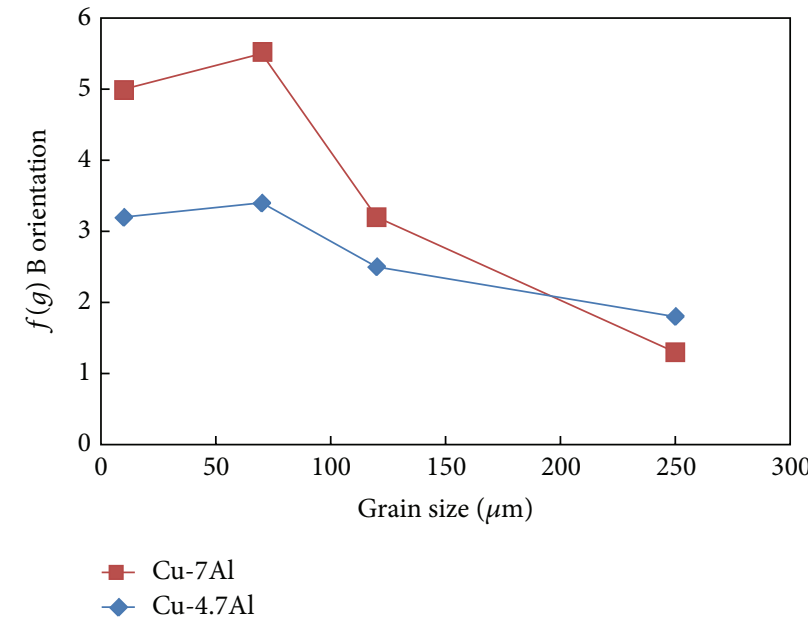

FIGURE 12: Variation of the orientation density $f(g)$ values for the B orientation for $\mathrm{Cu}-4.7 \mathrm{Al}$ and $\mathrm{Cu}-7 \mathrm{Al}$, with four different initial grain sizes, plane strain compressed to a true strain of 1.0.

TABLE 3: Orientation density $f(g)$ values for the B orientation for two grain sized $70 / 30$ brass $[25,30]$.

\begin{tabular}{|c|c|c|c|c|}
\hline \multicolumn{5}{|c|}{$2-5 \mu \mathrm{m} 70 / 30$ brass (ref. [30]) } \\
\hline Rolling reductions & $20 \%$ & $40 \%$ & $80 \%$ & $88 \%$ \\
\hline Orientation density $f(g)$ & 6 & 7 & 11 & 16 \\
\hline \multicolumn{5}{|c|}{$35 \mu \mathrm{m} 70 / 30$ brass (ref. [25]) } \\
\hline Rolling reductions & $20 \%$ & $40 \%$ & $80 \%$ & $90 \%$ \\
\hline Orientation density $f(g)$ & 3 & 3 & 9 & 11 \\
\hline
\end{tabular}

\section{Conclusion}

(1) Stacking fault energy (SFE) has an indirect effect on twinning initiation in a sense that low SFE promotes strain hardening in stage A which is due to the inhibition of dynamic recovery process such as cross slip and this leads to the fast build-up of the critical dislocation density required to initiate twinning.

(2) Grain size has a direct effect in controlling twin initiation, and a criterion relating the critical dislocation density associated with twinning to the initial grain size is empirically developed as power law as

$$
\left[\frac{\left(\sigma_{t}-\sigma_{o}\right)}{G}\right]=0.28 d^{-0.99}
$$

where $\sigma_{t}$ is the flow stress at which twinning starts, $\sigma_{o}$ is the yield strength, $G$ is the shear modulus, and $d$ is the average grain size in $\mu \mathrm{m}$.

(3) The value of $\left[\left(\sigma_{t}-\sigma_{o}\right) / G\right]$ for all materials tested (which have different SFE) at the same grain size was almost identical. This value, however, pronouncedly changes with grain size, for example, 0.0012 for $250 \mu \mathrm{m}$ and 0.0042 for $70 \mu \mathrm{m}$.

(4) Increasing the grain size reduces the critical dislocation density needed for twin initiation.
(5) For the low SFE alloys (Cu-4.7 Al and $\mathrm{Cu}-7 \mathrm{Al})$, the intensity of the $\mathrm{B}$ component is reduced with the large grain size $(\sim 250-280 \mu \mathrm{m})$ where the shear banding was scarcely notable. On the other hand, the B component is more pronounced in the $15 \mu \mathrm{m}$ and $70 \mu \mathrm{m}$ grain sized alloys, where the shear banding localization was more marked in the microstructure as a major feature.

\section{Conflict of Interests}

The authors declare that there is no conflict of interests regarding the publication of this paper.

\section{Acknowledgment}

This project was supported by King Saud University, Deanship of Scientific Research, College of Engineering, Research Centre.

\section{References}

[1] S. Asgari, E. El-Danaf, S. R. Kalidindi, and R. D. Doherty, "Strain hardening regimes and microstructural evolution during large strain compression of low stacking fault energy fee alloys that form deformation twins," Metallurgical and Materials Transactions A: Physical Metallurgy and Materials Science, vol. 28, no. 9, pp. 1781-1795, 1997.

[2] E. El-Danaf, S. R. Kalidindi, and R. D. Doherty, "Influence of grain size and stacking-fault energy on deformation twinning in fcc metals," Metallurgical and Materials Transactions A: Physical Metallurgy and Materials Science, vol. 30, no. 5, pp. 1223-1233, 1999.

[3] L. Rémy, "The interaction between slip and twinning systems and the influence of twinning on the mechanical behavior of fcc metals and alloys," Metallurgical Transactions A, vol. 12, no. 3, pp. 387-408, 1981.

[4] J. A. Venables, "The nucleation and propagation of deformation twins," Journal of Physics and Chemistry of Solids, vol. 25, no. 7, pp. 693-700, 1964.

[5] Y. Zhang, N. R. Tao, and K. Lu, "Effect of stacking-fault energy on deformation twin thickness in Cu-Al alloys," Scripta Materialia, vol. 60, no. 4, pp. 211-213, 2009.

[6] A. Rohatgi, K. S. Vecchio, and G. T. Gray III, "The influence of stacking fault energy on the mechanical behavior of $\mathrm{Cu}$ and $\mathrm{Cu}-$ al alloys: deformation twinning, work hardening, and dynamic recovery," Metallurgical and Materials Transactions A: Physical Metallurgy and Materials Science, vol. 32, no. 1, pp. 135-145, 2001.

[7] M. A. Meyers, O. Vöhringer, and V. A. Lubarda, "The onset of twinning in metals: a constitutive description," Acta Materialia, vol. 49, no. 19, pp. 4025-4039, 2001.

[8] L. Rémy and A. Pineau, "Twinning and strain-induced f.c.c. $\longrightarrow$ h.c.p. transformation on the mechanical properties of Co-NiCr-Mo alloys," Materials Science and Engineering, vol. 26, no. 1, pp. 123-132, 1976.

[9] Y. S. Han and S. H. Hong, "The effect of $\mathrm{Al}$ on mechanical properties and microstructures of Fe-32Mn-12Cr-xAl-0.4C cryogenic alloys," Materials Science and Engineering A, vol. 222, no. 1, pp. 76-83, 1997.

[10] G. T. Gray III, “Deformation twinning in Al-4.8 wt\% Mg," Acta Metallurgica, vol. 36, no. 7, pp. 1745-1754, 1988. 
[11] E. Romhanji, V. Milenkovic, and D. Drobnjak, "Grain size and alloying influence on the strain hardening of polycrystalline $\alpha$ brasses," Zeitschrift für Metallkunde, vol. 83, no. 2, pp. 110-114, 1992.

[12] S. S. Vadlamani, J. Eickemeyer, L. Schultz, and B. Holzapfel, "Rolling and recrystallisation textures in $\mathrm{Cu}-\mathrm{Al}, \mathrm{Cu}-\mathrm{Mn}$ and $\mathrm{Cu}-\mathrm{Ni}$ alloys," Journal of Materials Science, vol. 42, no. 17, pp. 7586-7591, 2007.

[13] V. Caballero and S. K. Varma, "Effect of stacking fault energy and strain rate on the microstructural evolution during room temperature tensile testing in $\mathrm{Cu}$ and $\mathrm{Cu}-\mathrm{Al}$ dilute alloys," Journal of Materials Science, vol. 34, no. 3, pp. 461-468, 1999.

[14] P. C. J. Gallagher, "The influence of alloying, temperature, and related effects on the stacking fault energy," Metallurgical Transactions, vol. 1, no. 9, pp. 2429-2461, 1970.

[15] E. A. El-Danaf, A. Al-Mutlaq, and M. S. Soliman, "Role of stacking fault energy on the deformation characteristics of copper alloys processed by plane strain compression," Materials Science and Engineering A, vol. 528, no. 25-26, pp. 7579-7588, 2011.

[16] C. B. Carter and I. L. F. Ray, "On the stacking-fault energies of copper alloys," Philosophical Magazine, vol. 35, no. 1, pp. 189200, 1977.

[17] C. B. Carter and P. B. Hirsch, "The formation and glide of jogs in low stacking-fault energy face-centred cubic materials," Philosophical Magazine, vol. 35, no. 6, pp. 1509-1522, 1977.

[18] S. R. Kalidindi, A. Abusafieh, and E. El-Danaf, "Accurate characterization of machine compliance for simple compression testing," Experimental Mechanics, vol. 37, no. 2, pp. 210-215, 1997.

[19] W. Z. Han, Z. F. Zhang, S. D. Wu, and S. X. Li, "Investigation on the geometrical aspect of deformation during equal-channel angular pressing by in-situ physical modeling experiments," Materials Science and Engineering A, vol. 476, no. 1-2, pp. 224229, 2008.

[20] I. Gutierrez-Urrutia, S. Zaefferer, and D. Raabe, "The effect of grain size and grain orientation on deformation twinning in a Fe-22wt.\% Mn-0.6wt.\% C TWIP steel," Materials Science and Engineering A, vol. 527, no. 15, pp. 3552-3560, 2010.

[21] P. Dobroň, F. Chmelík, S. Yi, K. Parfenenko, D. Letzig, and J. Bohlen, "Grain size effects on deformation twinning in an extruded magnesium alloy tested in compression," Scripta Materialia, vol. 65, no. 5, pp. 424-427, 2011.

[22] B. J. Duggan, M. Hatherly, W. B. Hutchinson, and P. T. Wakefield, "Deformation structures and textures in cold-rolled 70:30 brass," Metal Science, vol. 12, no. 8, pp. 343-351, 1978.

[23] A. A. S. Mohammed, E. A. El-Danaf, and A. A. Radwan, "A criterion for shear banding localization in polycrystalline FCC metals and alloys and critical working conditions for different microstructural variables," Journal of Materials Processing Technology, vol. 186, no. 1-3, pp. 14-21, 2007.

[24] J. Hirsch and K. Lücke, "Mechanism of deformation and development of rolling texture in polycrystaline fcc metals-I," Acta Metallurgica, vol. 36, no. 11, pp. 2863-2882, 1988.

[25] J. Hirsch, K. Lucke, and M. Hatherly, "Mechanism of deformation and development of rolling texture in polycrystaline fcc metals-III," Acta Metallurgica, vol. 36, pp. 2905-2927, 1988.

[26] H.-R. Wenk and P. Van Houtte, "Texture and anisotropy," Reports on Progress in Physics, vol. 67, no. 8, pp. 1367-1428, 2004.

[27] T. Leffers and R. K. Ray, "The brass-type texture and its deviation from the copper-type texture," Progress in Materials Science, vol. 54, no. 3, pp. 351-396, 2009.
[28] J. G. Sevillano, P. van Houtte, and E. Aernoudt, “The contribution of macroscopic shear bands to the rolling texture of FCC metals," Scripta Metallurgica, vol. 11, no. 7, pp. 581-585, 1977.

[29] E. El-Danaf, S. R. Kalidindi, R. D. Doherty, and C. Necker, "Deformation texture transition in brass: critical role of microscale shear bands," Acta Materialia, vol. 48, no. 10, pp. 26652673, 2000 .

[30] W. Y. Yeung, J. Hirsch, and M. Hatherly, "Rolling and annealing of fine grained 70:30 brass," Textures and Microstructures, vol. 10, pp. 135-152, 1989. 

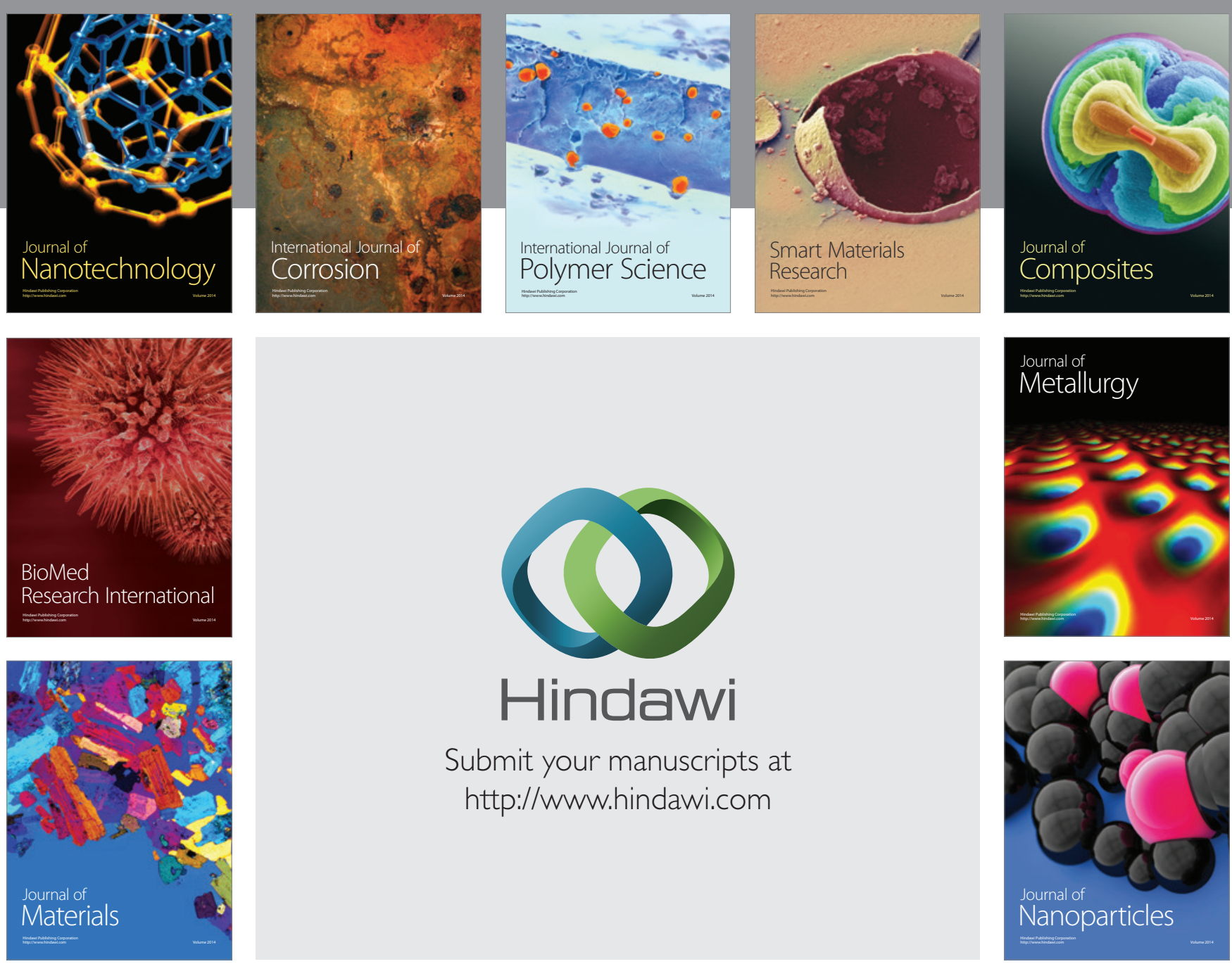

Submit your manuscripts at http://www.hindawi.com
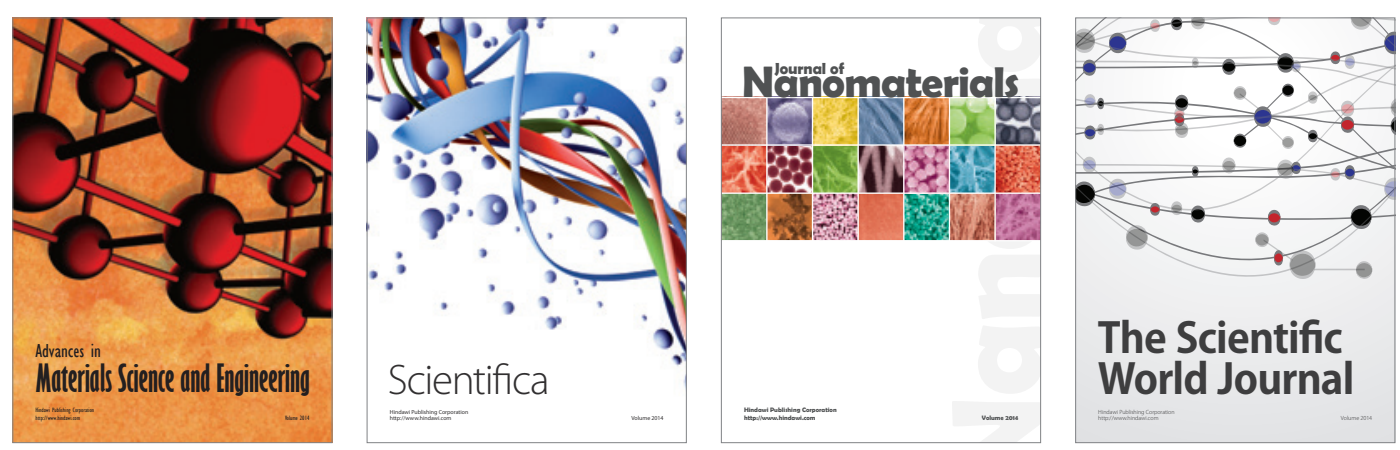

\section{The Scientific World Journal}
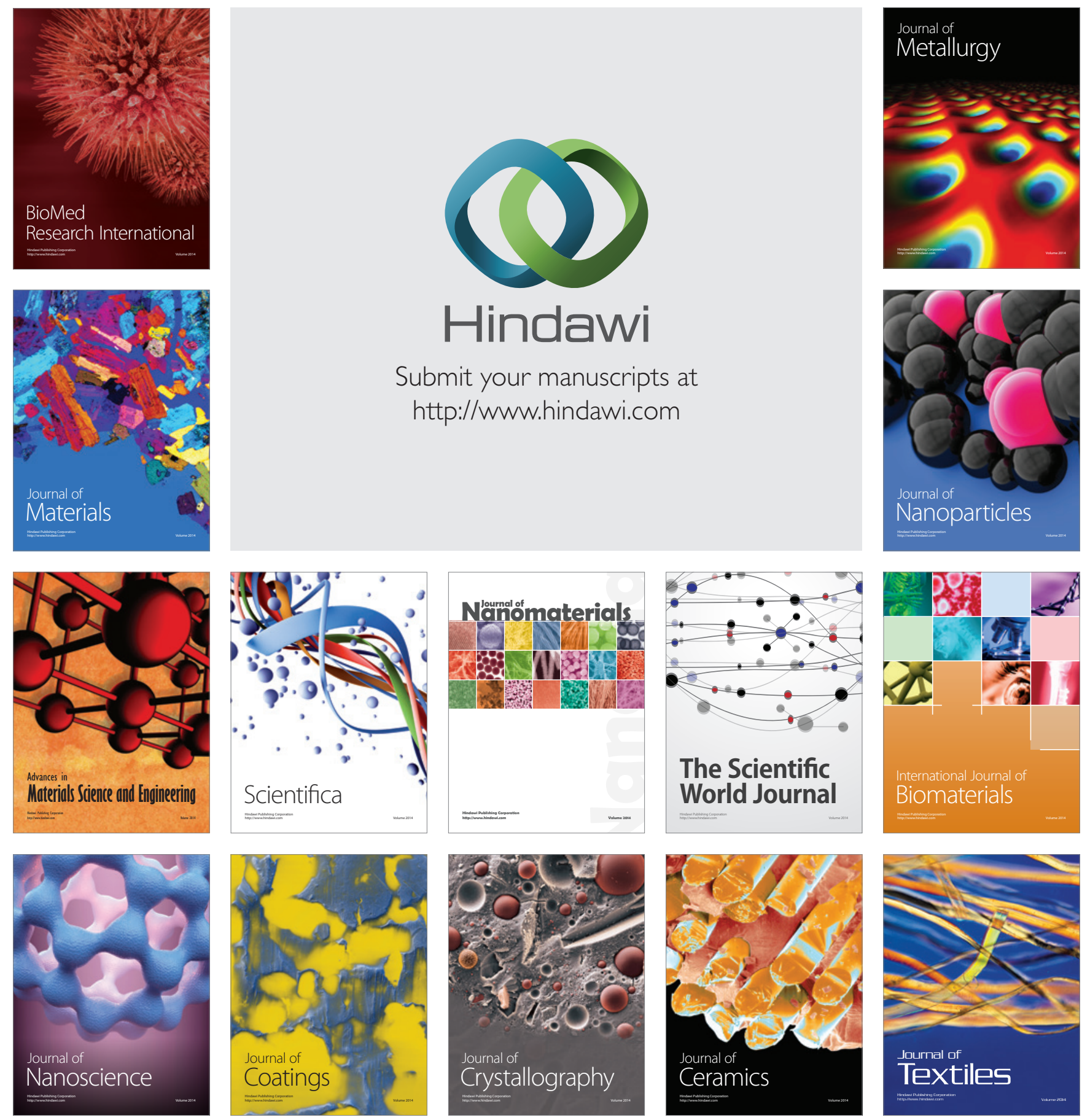